\title{
RELATIONSHIP BETWEEN FRAMING BIAS AND BIG FIVE PERSONALITY TRAITS OF INDIVIDUAL INVESTERS
}

\author{
Dr. Abhishek Sachan \\ Prof. (Dr.) Pawan K. Chugan
}

\begin{abstract}
Returns depend upon decisions of investors, but investors biases challenge the ability to take rational decisions. Study of biases and their relationships with personality traits helps to understand how biases originate, the way in which they possibly effect investors, and which personality types could be more susceptible to them. There are evidences that biases have relationships with personality traits of investors and this study focuses on one such relationship between framing bias and personality traits. Given the qualitative nature of variables under study, the relationship was established by statistically significant coefficients of logistic regression equation, where bias-variable was dependent and big five personality traits were independent. The score of personality trait, which had significant relationship, was cross tabulated with bias variable, the chi square test indicated a statistically significant relationship. The results lead to conclusion that an investor with higher score of agreeableness has higher probability of having framing bias. It is also discussed that an agreeable person may demonstrate irrationality discussed in prospect theory, more as compared to others, as the framing effects were measured using gain and loss frames. Since the study deals with frames of communication, it indicates towards the effects of personality traits on communication between portfolio manager and clients. The study contributes for portfolio managers that an agreeable client may not actually agree for rational decision if the communication is not in right frame.
\end{abstract}

Keywords Behavioral Biases, Personality Traits, Agreeableness, Framing Bias, Behavioral Finance, Investor decisions, Behavioral Economics.

\section{Introduction}

Understanding the decision process of an investor is necessary for client-advisor relationship, this can help advisors to achieve most optimal portfolio in accordance to the taste and knowledge of their client, also, fulfilling if not all, but many of the principles of standard finance. Renu \& Christie [18] suggest that the knowledge of behavioral factors expressed by each investor personality helps financial advisors to be well equipped to guide the investors in making the right investment decisions. 
Towards Excellence: An Indexed, Refereed \& Peer Reviewed Journal of Higher Education /Dr. Abhishek Sachan \& Prof.(Dr.) Pawan Chugan/ Page 665-676

Standard finance has limited acceptability to investors given their varied personalities and life experiences, as by Statman [23], the world of standard finance models people as "rational," whereas in behavioral finance people are modeled as "normal." He also describes Standard finance as the body of knowledge contributed by arbitrage principles of Miller and Modigliani, the portfolio principles of Markowitz, the capital asset pricing theory of Sharpe, Lintner, and Black, and the option pricing theory of Black, Scholes, and Merton. It is simply untrue to assume that investors understand these principles and take account of standard finance before making investment decisions, Keynes [7] proposed, "no human can be fully informed of all circumstances and maximize his expected utility by determining his complete, reflexive, transitive, and continuous preferences over alternative bundles of consumption goods at all times."

Behavioral finance addresses limitations of investors and helps for better financial decision as it tries to analyze a "real" person's thought process in decision making, Raiffa [17] discusses three approaches: Normative Analysis - it is concerned with the rational and ideal solutions, Descriptive Analysis - it is concerned with the manner in which real people actually make decisions and Prescriptive Analysis - it is concerned with practical advice and tools that might help people achieve results approximating to normative analysis. Raiffa [17] further adds that, standard finance may be considered more of normative, behavioral finance as more of descriptive and efforts to use behavioral finance in practice as prescriptive. [19]

\section{Literature Review}

Two of the important prescriptive frameworks have been provided by Shefrin \& Statman [21] and Pompian \& Longo [16]. Shefrin and Statman [22] developed Behavioral Portfolio Theory (BPT) and presented its two versions: BPT-SA, where the portfolio is integrated into a single mental account and BPT-MA, where the portfolio resembles layered pyramids with each layer mapping to respective mental account (aspiration level) of investor. Pompian and Longo [16], offer two propositions for helping a private wealth manager to counsel and help in decision making of a client:

- Proposition I: For a wealthier client, the advisor should adapt to client's behavioral biases, for a less wealthy client, the advisor must counsel and moderate client's biases.

- Proposition II: Clients exhibiting cognitive errors, which stem due to inefficiency to information procurement and processing of clients, should be moderated; and the clients exhibiting emotional biases, which stem due to impulse, intuition and feelings, should be adapted.

In the above discussion it is visible that behaviorally modified asset allocation deals with investor's biases, counseling of investors and providing proper information to investors for correct decision making; all based upon investor profile (wealth) and investor's biases. Hence a private wealth manager may have to understand the nuances of investor biases and personality of investors (for counseling purposes).

Biases of individual market participants are studied as emotional biases and cognitive errors. Framing bias stems due to cognitive limitations of individuals. Cognitive errors indicate towards limitations of individuals for basic information processing. Broadly, cognitive errors may stem from inability to understand statistics, memory errors, improper reasoning, and underweighting/overweighting new 
Towards Excellence: An Indexed, Refereed \& Peer Reviewed Journal of Higher Education /Dr.

Abhishek Sachan \& Prof.(Dr.) Pawan Chugan/ Page 665-676

information. The good thing about them is that to an extent they can be corrected by educating clients. Tversky \& Kahneman [26] see framing bias when a person answers a question differently based on the way in which it is framed. Investor having framing bias could affect investment decisions differently on same information if it is presented in different frames, viz. positive or negative

Behavior of individuals can be predicted based on their personalities; extending this idea to individual investors, case for study of relationship between behavioral biases and personalities of individual investors holds proper grounds. The basic idea is, for investors exhibiting certain kind of personality traits, a relationship with investment decisions may be possible. The meta-analysis of the literature connected to this thought and idea is reported in Table 1. Big Five Personality Traits by McCrae \& Costa [10] have been defined as:

- Agreeableness - (Being helpful, trusting and sympathetic) Vs (self-interested, quarrelsome)

- Openness - (active imagination, divergent thinking, curiosity) Vs (conventional, prefer familiar things)

- Conscientiousness - (Self-discipline, organized, determined) Vs (careless, easily distracted, undependable)

- Neuroticism - (easily upset, sad and anxious) Vs (calm, well adjusted)

- Extraversion - (social, energetic, optimistic) Vs (reserved, even paced)

Table 1

Review of Behavioral Biases and Personality Parameters

\begin{tabular}{|c|c|c|c|c|}
\hline Author & Related Conclusions of Study & $\begin{array}{l}\text { Sample } \\
\text { Size }\end{array}$ & $\begin{array}{l}\text { Statistical } \\
\text { Tools }\end{array}$ & Country \\
\hline $\begin{array}{ll}\text { Lerner } & \& \\
\text { Keltner [9] } & \end{array}$ & $\begin{array}{l}\text { "Fear and anger have opposite } \\
\text { effects on risk perception. Whereas } \\
\text { fearful people expressed pessimistic } \\
\text { risk estimates and risk-averse } \\
\text { choices, angry people expressed } \\
\text { optimistic risk estimates and risk- } \\
\text { seeking choices." }\end{array}$ & 75 & $\begin{array}{l}\text { Mixed design } \\
\text { regression }\end{array}$ & US \\
\hline Parashar [14] & $\begin{array}{l}\text { "The investment choice depends on } \\
\text { and is affected by the demographic } \\
\text { variables such as gender, age, } \\
\text { income, education, occupation as } \\
\text { well as various personality types } \\
\text { such as conservative, medium } \\
\text { conservative, moderate, medium } \\
\text { aggressive and aggressive." }\end{array}$ & 100 & $\begin{array}{l}\text { Descriptive } \\
\text { Statistics and } \\
\text { Factor } \\
\text { Analysis }\end{array}$ & India \\
\hline $\begin{array}{l}\text { Jamshidinavid, } \\
\text { Chavoshani, \& } \\
\text { Amiri [6] }\end{array}$ & $\begin{array}{l}\text { The results show that the } \\
\text { investment prejudices in individual } \\
\text { investigators has relationship with }\end{array}$ & 215 & $\begin{array}{l}\text { Structure } \\
\text { Equation } \\
\text { Modelling }\end{array}$ & Tehran \\
\hline
\end{tabular}


Towards Excellence: An Indexed, Refereed \& Peer Reviewed Journal of Higher Education /Dr.

Abhishek Sachan \& Prof.(Dr.) Pawan Chugan/ Page 665-676

\begin{tabular}{|c|c|c|c|c|}
\hline & $\begin{array}{l}\text { personal characteristics (big five) } \\
\text { meaningfully and with some of the } \\
\text { demographic variables weakly. }\end{array}$ & & & \\
\hline $\begin{array}{l}\text { Moradi, } \\
\text { Mostafaei, \& } \\
\text { Meshki [11] }\end{array}$ & $\begin{array}{l}\text { There were some interrelationships } \\
\text { between personality dimensions } \\
\text { with perceptual illusion in Stock } \\
\text { Exchange of Tehran. The results of } \\
\text { first hypothesis also show that there } \\
\text { was a relationship between } \\
\text { extroversion-introversion and data } \\
\text { availability bias. }\end{array}$ & & $\begin{array}{l}\text { Chi Square } \\
\text { and Phi tests }\end{array}$ & Tehran \\
\hline $\begin{array}{l}\text { Sahi, Arora, \& } \\
\text { Dhameja [20] }\end{array}$ & $\begin{array}{l}\text { "An understanding of an individual } \\
\text { investor's psychology would help in } \\
\text { better comprehending the way the } \\
\text { individual investment decisions are } \\
\text { made." }\end{array}$ & 30 & $\begin{array}{l}\text { Qualitative } \\
\text { Analysis, } \\
\text { Open } \\
\text { Analysis }\end{array}$ & India \\
\hline $\begin{array}{l}\text { Nga \& Ken Yien } \\
{[12]}\end{array}$ & $\begin{array}{l}\text { "Conscientiousness, openness and } \\
\text { agreeableness were found to have a } \\
\text { significant influence on risk } \\
\text { aversion, cognitive biases and SRI } \\
\text { respectively. Gender and course } \\
\text { majors taken were not significant in } \\
\text { financial decision making." }\end{array}$ & 346 & $\begin{array}{l}\text { Multiple } \\
\text { linear } \\
\text { regressions, } \\
\text { t-tests and } \\
\text { ANOVA }\end{array}$ & $\begin{array}{c}\text { Malaysi } \\
\text { a }\end{array}$ \\
\hline $\begin{array}{l}\text { Tauni, Fang, \& } \\
\text { Iqbal [24] }\end{array}$ & $\begin{array}{l}\text { "Financial advisors tend to increase } \\
\text { the frequency of trading in investors } \\
\text { with openness, extraversion, } \\
\text { neuroticism and agreeableness } \\
\text { personality traits, and tend to } \\
\text { decrease the intensity of trading in } \\
\text { investors with conscientiousness } \\
\text { trait." }\end{array}$ & 541 & $\begin{array}{l}\text { Probit } \\
\text { Regression } \\
\text { Analysis }\end{array}$ & China \\
\hline $\begin{array}{l}\text { Tauni, Fang, \& } \\
\text { Iqbal [25] }\end{array}$ & $\begin{array}{l}\text { "Investors with extraversion and } \\
\text { agreeableness traits trade stocks } \\
\text { more intensively when they acquire } \\
\text { information via word-of-mouth } \\
\text { communication. Open minded, } \\
\text { conscientious and neurotic } \\
\text { investors adjust their portfolio less } \\
\text { frequently as a result of social } \\
\text { interaction." }\end{array}$ & 541 & & China \\
\hline Oehler, Wendt, & "More extraverted individuals pay & 364 & Survey & German \\
\hline
\end{tabular}


Towards Excellence: An Indexed, Refereed \& Peer Reviewed Journal of Higher Education /Dr. Abhishek Sachan \& Prof.(Dr.) Pawan Chugan/ Page 665-676

\begin{tabular}{|l|l|l|l|l|}
\hline Wedlich, \& & $\begin{array}{l}\text { higher prices for financial assets and } \\
\text { they buy more financial assets when } \\
\text { assets are overpriced than less } \\
\text { extraverted individuals do. More } \\
\text { neurotic individuals hold less risky } \\
\text { assets in their financial portfolios } \\
\text { than less neurotic individuals do." }\end{array}$ & $\begin{array}{c}\text { based, with } \\
\text { experimental } \\
\text { asset market. }\end{array}$ & $\mathrm{y}$ \\
\hline
\end{tabular}

\section{Research Gap}

The literature in Table 1 broadly suggests possibility of finding relationship between personality traits and biases, however specific evidences are provided by Anderson [2] and Conroy [3] which suggest relationships between personality traits and framing bias. Anderson [2] suggests that agreeableness is the only personality trait that affects framing bias of an investor based upon prospect theory's loss and gain frame. Similarly, Conroy [3] suggests that personality traits like openness, agreeableness and conscientiousness mediate framing effects related to civil liberties, medical research and treatments, energy, affirmative action and gun control.

The literature reported presents a basis to pursue research on relationship between personality traits and framing bias.

\section{Research Methodology}

A primary research was conducted in which participants of the study were individual investors of Gujarat (a state of India). A questionnaire was prepared with some basic identifiers like name and contact number, items related to framing bias and TIPI. Ten Item Personality Measure Inventory (TIPI) designed by Gosling, Rentfrow, \& Swann [4] was used for measuring personality traits. TIPI has been tested across ethnicities with sufficiently large samples for reliability and validity; hence this instrument was adopted as it is. These traits are measured on 7-point Likert scale as per the design of the standard Ten Item Personality Inventory

The items measuring framing bias were picked from Pompian [15]. The questionnaire thus produced was pretested in three rounds, with respondents of different backgrounds but matching with target population and then necessary modifications were made. The items were translated to local language as per the suggestion of the pretesting participant, and translational validity was obtained in addition to test retest reliability.

The final questionnaire was face validated and checked for test-retest reliability. The test-retest correlations for individual variables are reported in table 2.

\section{Table 2}

\section{Test-Retest Correlations}

\begin{tabular}{|c|c|c|c|c|c|c|}
\hline Variable & E & A & C & ES & OE & FB \\
\hline Correlation & 0.74 & 0.82 & 0.83 & 0.81 & 0.77 & 0.76 \\
\hline
\end{tabular}


Towards Excellence: An Indexed, Refereed \& Peer Reviewed Journal of Higher Education /Dr. Abhishek Sachan \& Prof.(Dr.) Pawan Chugan/ Page 665-676

All Correlations significant at $\alpha=0.01$

FB - Framing Bias score, Other variables are defined in

hypothesis section 4.2

\section{Sampling}

Sample size was calculated using the below equation (1),

$$
n=(Z \alpha / 2) 2 p(1-p) / \operatorname{Er} 2
$$

Where,

$\mathrm{Z} \alpha / 2$ is value of standard normal distribution for $\alpha$ significance level

$\mathrm{P} \quad$ is the proportion reported by the study

$\mathrm{Er} \quad$ is the desired margin of error

Looking at the broad definition of individual investors, we have considered population to be infinite, by using $\mathrm{p}=0.5$ (for maximum possible sample size) and selecting $\mathrm{Er}=5 \%$ and $\alpha=5 \%$ (standard practice), the value of ' $n$ ' was found to be 384, and this was the sample size which was targeted. Assuming a 50\% response rate, 768 respondents were contacted and a total of 516 useful responses were recorded, the sample size was well above the statistical requirement. Investors or participants of the study were identified as:

- Investors investing their capital in their own accounts - e.g. salaried or self-employed individuals

- Investors investing other's capital in their own accounts - e.g. Dependents like parents, housewife, etc

- Investors investing other's capitals in others accounts - e.g. Financial Advisors

The commonality among our respondents was the ability to take investment decision for an available sum of capital. The frequency of investments was of lesser importance as due to some biases/experiences an individual may avoid frequent buying/selling [19].

After collecting all responses, the complete and clear responses were identified. Sampling process was respondent driven. Randomness of sample selection was maintained based on conditions as suggested by Lee \& Peters [8]:

- Each element selected comes from the defined population

- Each element is selected independently of other

Respondents of Indian State of Gujarat were targeted. It has five divisions: North, Central, South, Kutch (Kachh) and Saurashtra. The sample had proportionate representation of all five regions. Female and rural participation was low in number but adequate, as traditionally they are less active in investment decisions; however, tribal population has not been adequately represented in the sample due to researchers' limitations. Overall, the sample produces more than satisfactory representation of the population.

\section{Hypothesis}


Towards Excellence: An Indexed, Refereed \& Peer Reviewed Journal of Higher Education /Dr.

Abhishek Sachan \& Prof.(Dr.) Pawan Chugan/ Page 665-676

Here, big five personality traits have been measured on 7-point ordinal scale; while investor's biases are measured on nominal scale as $0 \mathrm{~s}$ and $1 \mathrm{~s}$. As the nature of data was categorical, and biases were assumed dependent on personality traits, hence the relationship between a bias and personality traits was established using binary logistic regressions. Based upon the method suggested by Agresti \& Kateri [1], with biases as dependent variables and five personality traits as the independent variables, following equation was tested:

$$
\ln \ln \left\lceil\frac{\hat{p}(F B)}{1-\hat{p}(F B)}\right\rceil=C R_{0}+C R_{1} \cdot E+C R_{2} \cdot A+C R_{3} \cdot C+C R_{4} \cdot E S+C R_{5} \cdot O E
$$

Where,

$$
\begin{aligned}
& \frac{\hat{p}(F B)}{1-\hat{p}(F B)}=\text { odds of Framing Bias, where FB is measured in nominal scale } \\
& \begin{array}{ll}
\hat{p}(F B) & =\text { probability that score of variable FB is ' } 1 \\
C R_{0} \text { to } C R_{5} & =\text { coefficients of regression to be found using binary logistic regression } \\
\text { E } & =\text { Score of extraversions } \\
\text { A } & =\text { Score of agreeableness } \\
\text { C } & =\text { Score of conscientiousness } \\
\text { ES } & =\text { Score of emotional stability } \\
\text { OE } & =\text { Score of openness to experience }
\end{array}
\end{aligned}
$$

The trait which had a regression coefficient significantly different from zero was marked to be related to the Framing bias. A negative statistically significant coefficient demonstrated negative relationship, while a positive statistically significant coefficient was indicative of positive relationship. Hence, the null hypotheses to be tested individually for five coefficients of logistic regression were:

H0: Regression coefficient of Big Five personality trait variable is equal to zero.

And respective alternate hypotheses to be tested were,

Ha: Regression coefficient of Big Five personality trait variable is not equal to zero.

As there are five personality traits, five of null and alternate hypotheses were tested.

\section{Results}

The binary logistic regression with framing bias as dependent and personality traits as independent variables suggested the relationship between framing bias and agreeableness. The null hypotheses that the regression coefficients of personality traits were not significantly different from zero were rejected for regression coefficient of agreeableness with $p=0.047$. The relationship is positive and hence suggests that investors with higher scores of agreeableness are more likely to be having framing bias. Tables 3 contains the output of logistic regression model.

Table 3. Final Logistic Regression Model

\begin{tabular}{|c|c|c|c|c|c|c|}
\hline & Coefficients & Standard Error & Wald & df & p-value & Exp(B) \\
\hline E & .102 & .073 & 1.931 & 1 & .165 & 1.107 \\
\hline
\end{tabular}


Towards Excellence: An Indexed, Refereed \& Peer Reviewed Journal of Higher Education /Dr. Abhishek Sachan \& Prof.(Dr.) Pawan Chugan/ Page 665-676

\begin{tabular}{|c|c|c|c|c|c|c|}
\hline $\mathrm{A}$ & .154 & .078 & 3.929 & 1 & .047 & 1.166 \\
\hline $\mathrm{C}$ & .052 & .072 & .532 & 1 & .466 & 1.054 \\
\hline $\mathrm{ES}$ & .025 & .078 & .103 & 1 & .748 & 1.025 \\
\hline $\mathrm{OE}$ & -.020 & .078 & .068 & 1 & .795 & .980 \\
\hline Constant & -1.009 & .591 & 2.915 & 1 & .088 & .365 \\
\hline
\end{tabular}

The results in Table 3 suggest that coefficient of regression of agreeableness was not zero, or the null hypothesis was rejected in this case. This suggests that agreeableness is related with framing bias. The direction of relationship is positive, or if an investor has higher score of agreeableness then he/she is more probable to have framing bias.

\section{Discussion}

The data suggests that $61.6 \%$ of investors demonstrated framing bias and $44 \%$ of total investors had higher scores of agreeableness (greater than 5). If we divide the agreeableness scores in three bands as:

- Low Score (LS): Scores less than 3.

- Medium Score (MS): Scores between 3 and 5 (both inclusive).

- High Score (HS): Scores greater than 5.

We obtain the following cross tabulation:

Table 4. Agreeableness and Framing Bias Cross Table

\begin{tabular}{|cccccc|}
\hline \multicolumn{5}{|c}{ Framing Bias \& Score Cross Tabulation } \\
\hline & & \multicolumn{3}{c|}{ Score - Count } & \multirow{2}{*}{ Total } \\
\cline { 2 - 5 } & & HS & LS & MS & \\
\hline $\begin{array}{c}\text { Framing } \\
\text { Bias }\end{array}$ & 0 & 74 & 11 & 113 & 198 \\
\hline \multicolumn{2}{c}{1} & 153 & 10 & 155 & 318 \\
\hline Total & 227 & 21 & 268 & 516 \\
\hline
\end{tabular}

The above cross tabulation suggests that major of the population is having medium and high score of agreeableness. Looking at the high score band, we find that a person in this band is twice likely to be affected with framing bias (ratio of 153/74). This table also gives us visibility of relationship between framing bias and agreeableness scores. The chi-square value of above tabulation is 6.57 with $\mathrm{p}$-value $=$ 0.037 .

\section{Implications of the Study}

Hirsh, Kang, \& Bodenhausen [5] suggest that messages must be tailored based upon the recipient's personality traits, this increases effectiveness of communication. They also demonstrated that messageperson congruence can be established using framing effects targeting specific personality traits. This 
Towards Excellence: An Indexed, Refereed \& Peer Reviewed Journal of Higher Education /Dr. Abhishek Sachan \& Prof.(Dr.) Pawan Chugan/ Page 665-676

supports the argument that portfolio managers must explore personality of clients for making effective communication.

Specifically, for clients high on agreeableness, who are expected to register loss frames with a double likelihood, persuading them to lock most optimal investments may be challenging. These clients may sound agreeable and compassionate during manager-client interaction but they may ultimately refuse the suggested optimal investment if the framing of promotional material or investment policy statements is not proper. This research thus emphasizes upon the selective communication with proper frames in order to lead clients to an optimum portfolio.

Another perspective from this study is in its relation to prospect theory. As per the theory, investors make decisions based on the potential of losses and gains of an investment, rather than on the expected value; investors evaluate potential losses and gains using some heuristics, such that they become risk averse for gains and risk seeker for losses. In this study, the respondents were asked to choose among similar situations, but presented in negative and positive frames, the study indicates that an agreeable person has way more impact of negative frames/prospects than persons high on other personality traits, hence an agreeable person may also demonstrate higher probability of following prospect theory.

\section{Scope of Future Research}

It will be interesting to further explore the reasons for why agreeable investors demonstrate framing bias, and how should the communication be designed to help investors reach the optimum portfolios. A further exploration may develop necessary process algorithms that may help managers succeed to not only design optimum portfolios but also execute it for client because they could communicate it well.

In addition to designing optimum portfolio, an interesting investigation can be related to effects of personality traits on trading frequency.

As a scope for future, researchers may study other biases and their interaction with personality. A sophisticated algorithm may be developed for seeking validation of identified biases, via personality traits.

\section{Conclusion}

This study derives statistically significant relationship between framing bias of individual investors and agreeableness using logistic regression and cross-tabulation. The direction of relationship is positive, higher the presence of trait of agreeableness, higher is the probability that investor demonstrates framing bias in decision making. The research creates potential in improving client and manager relationship as portfolio managers may put communication in correct frames to assist client's decision-making process, especially agreeable clients

\section{Limitations of the Study}


Towards Excellence: An Indexed, Refereed \& Peer Reviewed Journal of Higher Education /Dr.

\section{Abhishek Sachan \& Prof.(Dr.) Pawan Chugan/ Page 665-676}

This study must be generalized with caution as it has participants of only one state of India, i.e. Gujarat. The study also has statistical limitations as the variables studied were of nominal and ordinal nature, causing limited statistical analysis. However limited, but the statistical treatments reported in this study were sufficient to establish the hypotheses.

Although a scientific approach has been used, but study reports relationship between qualitative factors, which have limitations of measurements, hence standard cautions must be exercised. 
Towards Excellence: An Indexed, Refereed \& Peer Reviewed Journal of Higher Education /Dr.

\section{Abhishek Sachan \& Prof.(Dr.) Pawan Chugan/ Page 665-676}

\section{Works Cited}

Agresti, A., \& Kateri, M. Categorical data analysis: Springer. 2011.

Anderson, K. D. Framing Traits: The Role of Personality in Framing Effects. University of Nebraska at Lincoln. 2010.

Conroy, M. A psychology of framing: The effects of personality on susceptibility to media frames: University of California, Santa Barbara. 2010.

Gosling, S. D., Rentfrow, P. J., \& Swann, W. B. A very brief measure of the Big-Five personality domains. Journal of Research in personality, 37(6), 504-528. 2003.

Hirsh, J. B., Kang, S. K., \& Bodenhausen, G. V. Personalized persuasion tailoring persuasive appeals to recipients' personality traits. Psychological science, 23(6), 578-581. 2012.

Jamshidinavid, B., Chavoshani, C., \& Amiri, S. The Impact of Demographic and Psychological Characteristics on the Investment Prejudices in Tehran Stock. European Journal of Business and Social Sciences, 1(5), 41-53. 2012.

Keynes, J. M. The General Theory of Employment, Interest, and Money, New York: H arcourt, Brace \& World: Inc. 1936.

Lee, N., \& Peters, M. Business Statistics Using EXCEL and SPSS: SAGE. 2015.

Lerner, J. S., \& Keltner, D. Fear, anger, and risk. Journal of personality and social psychology, 81(1), 146. 2001.

McCrae, R. R., \& Costa, P. T. Validation of the five-factor model of personality across instruments and observers. Journal of personality and social psychology, 52(1), 81. 1987.

Moradi, M., Mostafaei, Z., \& Meshki, M. A study on investors' personality characteristics and behavioral biases: Conservatism bias and availability bias in the Tehran Stock Exchange. Management Science Letters, 3(4), 1191-1196. 2013.

Nga, J. K., \& Ken Yien, L. The influence of personality trait and demographics on financial decision making among Generation Y. Young Consumers, 14(3), 230-243. 2013.

Oehler, A., Wendt, S., Wedlich, F., \& Horn, M. Investors' Personality Influences Investment Decisions: Experimental Evidence on Extraversion and Neuroticism. Journal of behavioral finance, 19(1), 30-48. 2018.

Parashar, N. An Empirical Study on Personality Variation and Investment Choice of Retail Investors. Journal of Management and Information Technology, 2(1), 33-42. 2010.

Pompian, M. M. Behavioral finance and wealth management. How to build optimal portfolios for private clients. 2006.

Pompian, M. M., \& Longo, J. M. Incorporating Behavioral Finance into Your Practice. Journal of Financial Planning, 18(3). 2005. 
Towards Excellence: An Indexed, Refereed \& Peer Reviewed Journal of Higher Education /Dr. Abhishek Sachan \& Prof.(Dr.) Pawan Chugan/ Page 665-676

Raiffa, H. Decision analysis: Introductory readings on choices under uncertainty. Mc-Graw Hill, 309, 8. 1997.

Renu, I. R., \& Christie, P. Review of the influence of Investor Personality (The Big 5 Model) on Investor Behavior. International Journal of Research in Finance and Marketing, 7(7), 9-18. 2017

Sachan, Abhishek and Chugan, Pawan Kumar, Availability Bias of Urban and Rural Investors: Relationship Study of the Gujarat State of India, Journal of Behavioural Economics, Finance, Entrepreneurship, Accounting and Transport, Vol. 8, No. 1, 1-6, Published by Science and Education Publishing, USA, DOI:10.12691/jbe-8-1-1. 2020. Available at https://papers.ssrn.com/sol3/papers.cfm?abstract_id $=3664546$

Sahi, S. K., Arora, A. P., \& Dhameja, N. An exploratory inquiry into the psychological biases in financial investment behavior. Journal of behavioral finance, 14(2), 94-103. 2013.

Shefrin, H. M., \& Statman, M. Explaining investor preference for cash dividends. Journal of financial economics, 13(2), 253-282. 1984.

Shefrin, H., \& Statman, M. Behavioral capital asset pricing theory. Journal of financial and quantitative analysis, 29(03), 323-349. 1994.

Statman, M. Foreign stocks in behavioral portfolios. Financial Analysts Journal, 55(2), 12-16. 1999.

Tauni, M. Z., Fang, H. X., \& Iqbal, A. Information sources and trading behavior: does investor personality matter? Qualitative Research in Financial Markets, 8(2), 94-117. doi: doi:10.1108/QRFM08-2015-0031. 2016.

Tauni, M. Z., Fang, H. X., \& Iqbal, A. The role of financial advice and word-of-mouth communication on the association between investor personality and stock trading behavior: Evidence from Chinese stock market. Personality and individual differences, 108, 55-65. 2017.

Tversky, A., \& Kahneman, D. The framing of decisions and the psychology of choice. science, 211(4481), 453-458. 1981.

Dr. Abhishek Sachan

Quantile Analytics Private Limited, Indore, India

\&

Prof. (Dr.) Pawan K. Chugan

Visiting Professor - Institute of Management, Nirma University; AIIM

Ahmedabad, and PDPU Gandhinagar, India

Corresponding Author: pkchugan@gmail.com 